\section{International Scientific Journal Theoretical \& Applied Science}

\author{
p-ISSN: 2308-4944 (print) e-ISSN: 2409-0085 (online) \\ Year: $2016 \quad$ Issue: 5 Volume: 37 \\ Published: $30.05 .2016 \quad$ http://T-Science.org
}

Bauyrzhan Zharkynbekovich Manapbayev

Candidate of technical sciences, associate professor of the Department of «Oil and gas engineering»

M.Kh. Dulaty Taraz State University, Kazakhstan jiboj@mail.ru

Kenzhegali Koshkarbayevich Shilibek Candidate of technical sciences, Head of the organization and coordination of research works M.Kh. Dulaty Taraz State University, Kazakhstan

Olzhas Ongarovich Kozhas Managing laboratory of the Department of «Oil and gas engineering»

M.Kh. Dulaty Taraz State University, Kazakhstan

\title{
THE DEVICE FOR CLEARING OF SMOKE GASES AND HEAT RECYCLING
}

\author{
Abstract: In article the device for clearing of the smoke gases, applied in power, phosphoric, oil and gas, \\ metallurgical and in other industries where furnaces for burning of various fuel are used is offered. \\ Key words: clearing, smoke gases, heat recycling. \\ Language: Russian \\ Citation: Manapbayev BZ, Shilibek KK, Kozhas OO (2016) THE DEVICE FOR CLEARING OF SMOKE \\ GASES AND HEAT RECYCLING. ISJ Theoretical \& Applied Science, 05 (37): 119-122. \\ Soi: http://s-o-i.org/1.1/TAS-05-37-22 Doi: crossef http://dx.doi.org/10.15863/TAS.2016.05.37.22
}

\section{УСТРОЙСТВО ДЛЯ ОЧИСТКИ ДЫМОВЫХ ГАЗОВ И УТИЛИЗАЦИИ ТЕПЛА}

Аннотация: В статье предлагается устройство для очистки дымовых газов, применяемое в энергетической, фосфорной, нефтегазовой, металлургической и в других отраслях промышленности, где используются печи для сжигания различного топлива.

Ключевые слова: очистка, дымовые газы, утилизаџия тепла.

Влияние энергетической, фосфорной, нефтегазовой, металлургической и других отраслей промышленности на окружающую среду носит отрицательный характер. Основными проблемами при сжигании топлива является загрязнение окружающей среды окислами азота, серы, золой и т.П., а также повреждение зданий и сооружений $[1,2]$ из-за вредных выбросов. Также велико влияние сжигания топлива на парниковый эффект вследствие выбросов углекислого газа. Для уменьшения вредного воздействия на окружающую среду необходимо разрабатывать более эффективные технологии сжигания топлива.

С этой целью нами предложено устройство для очистки дымовых газов [3,4]. Оно относится к очистке дымовых газов от пыли, вредных газов, золы и сажи, твердых, жидких и газообразных компонентов, применяемых в энергетической, фосфорной, нефтегазовой, металлургической и в других отраслях промышленности, где используются печи для сжигания различного топлива. В мире имеются множество устройств для очистки дымовых газов [5-10]. Рассмотрим некоторые из них.

Известно устройство для очистки газов [5], содержащее вертикальный цилиндрический корпус с днищем и крышкой, частично заполненный жидким реагентом, выхлопную трубу, центральную кольцевую отражательную перегородку, расположенную над жидким реагентом газораспределительную трубу, соединенную с нагнетателем, ориентированную выходным концом к днищу корпуса и размещенную по оси к последнего, где с целью повышения эффективности процесса за счет увеличения времени контакта фаз, оно снабжено конусным отбойником, закрепленным на днище корпуса соосно с газораспределительной трубой и дополнительной отражательной перегородкой, погруженный в жидкий реагент и выполненной с центральным газоходным каналом, при этом отражательные перегородки выполнены выпуклыми по ходу газа. 
Недостатком данного устройства является использование жидкого реагента для промывки газа, не погружение газораспределительных труб в жидкость, использование только одной установки для очистки газа, также оборудование и переоборудование его различными дополнительными очистительными устройствами и средствами. Это приводит к сложности конструкции устройства, частой замене дорогостоящего жидкого реагента и последующим большим материальным затратам.

Известен аппарат для очистки газа [6] от твердых, жидких и/или газообразных примесей, содержащий резервуар, частично заполненный жидкостью, патрубок впуска газа, соединенный с ним распределительный элемент, сообщенный через соединительные трубы с распределительными насадками, заглубленными под уровень жидкости, патрубок выпуска газа, где с целью повышения эффективности работы входные отверстия соединительных труб, распределительные элементы, выходные отверстия распределительных насадок выполнены в различных видах, сечениях и на разных уровнях по высоте в корпусе, также аппарат снабжен разными перегородками, ребрами, стенками.

Недостатком данного аппарата является использование только одной установки для очистки газа, не использование нагнетателя для подачи газа с требуемым давлением под воду, также оборудование и переоборудование аппарата различными дополнительными очистительными устройствами и средствами. Это приводит к сложности конструкции устройства и последующим большим материальным затратам.

По сути, использование только одной установки для очистки дымовых газов от твердых, жидких и газообразных компонентов не дает большого и достаточного эффекта очистки.

Разработанное нами устройство для очистки газов [3,4], состоит из нагнетателя, установок очистки дымовых газов, содержащие бассейны с днищем и крышкой, частично заполненные водой, входные и выходные трубы. Оно отличается от других следующими параметрами:

1. Входная газораспределительная труба в верхней части бассейна горизонтально разветвляется на распределительные коллекторы и от них перпендикулярно заглубляются в закрытый бассейн в нижней части установки 18 трубок меньшего диаметра.

2. Над водой расположена преградительная сетка.

3. Имеется соединительная пропускная трубка.

4. Имеется специальная циркуляционная система водоснабжения.
5. Имеются газоанализаторы на выходных трубах.

6. Имеется дымоохладитель, в котором перпендикулярно закреплены перегородки, где газ перед тем, как попасть в закрытый бассейн, охлаждается до требуемой температуры.

7. За последней очистной установкой к системе через соединительную пропускную трубу соединен отстойник для загрязненной воды, выполненный в открытом виде без верхней крыши, имеющий верхний кран отбора чистой воды для повторного использования на циркуляционной системе и нижний кран для слива загрязненных осадков и опорожнения всей системы водоснабжения.

Задачей является разработка устройства с упрощенной конструкцией для очистки дымовых газов от пыли, вредных газов, золы и сажи, твердых, жидких и газообразных компонентов и утилизации тепла при данных работах. Это достигается тем, что до подачи дымового газа к установке его охлаждают и увеличивают давление. После дымовой газ вместо частично заполненного водой корпуса подают в закрытый бассейн, под определенным давлением газ омывается в бассейне и поднимается вверх. В газовом пространстве закрытого бассейна от поднимающегося газа увеличивается давление, и газ через выходную трубу проходит к следующей очистной установке. Весь этот процесс повторяется в одинаковых установках, переходя от одной установки к другой до полного или требуемого очищения дымовых газов от твердых, жидких и газообразных компонентов. Состав и уровень очищения газа контролируется специальными газоанализаторами на выходных трубах.

Устройство поясняется рис. 1, где представлена схема устройства для очистки дымовых газов, а также рис. 2, где представлен вид сверху одного закрытого бассейна для очистки дымовых газов. Перед тем как попасть в закрытый бассейн 9 дымовой газ охлаждается до требуемой температуры в дымоохладителе 1, имеющий перпендикулярно закрепленные перегородки 2, затем с помощью нагнетателя 7, расположенного на входной трубе 8, увеличивается давление дымового газа до $\begin{array}{llll}\text { требуемого и подается } & \text { через }\end{array}$ газораспределительные коллекторы 3 в 18 вертикально заглубленным трубкам 6 меньшего диаметра. Под давлением дымовой газ ударяется о дно бассейна и, омываясь, поднимается вверх бассейна. Над водой крупные частицы газового компонента ударяются об горизонтально установленную преградительную сетку 4, и газ дополнительно очищается от них. 


\begin{tabular}{l|lrl|l|ll} 
& ISRA (India) & $=\mathbf{1 . 3 4 4}$ & SIS (USA) & $=\mathbf{0 . 9 1 2}$ & ICV (Poland) & $=\mathbf{6 . 6 3 0}$ \\
Impact Factor: & ISI (Dubai, UAE) $=\mathbf{0 . 8 2 9}$ & PUHU (Russia) $=\mathbf{0 . 2 3 4}$ & PIF (India) & $=\mathbf{1 . 9 4 0}$ \\
& GIF (Australia) & $\mathbf{0 . 5 6 4}$ & ESJI (KZ) & $=\mathbf{1 . 0 4 2}$ & IBI (India) & $\mathbf{4 . 2 6 0}$
\end{tabular}

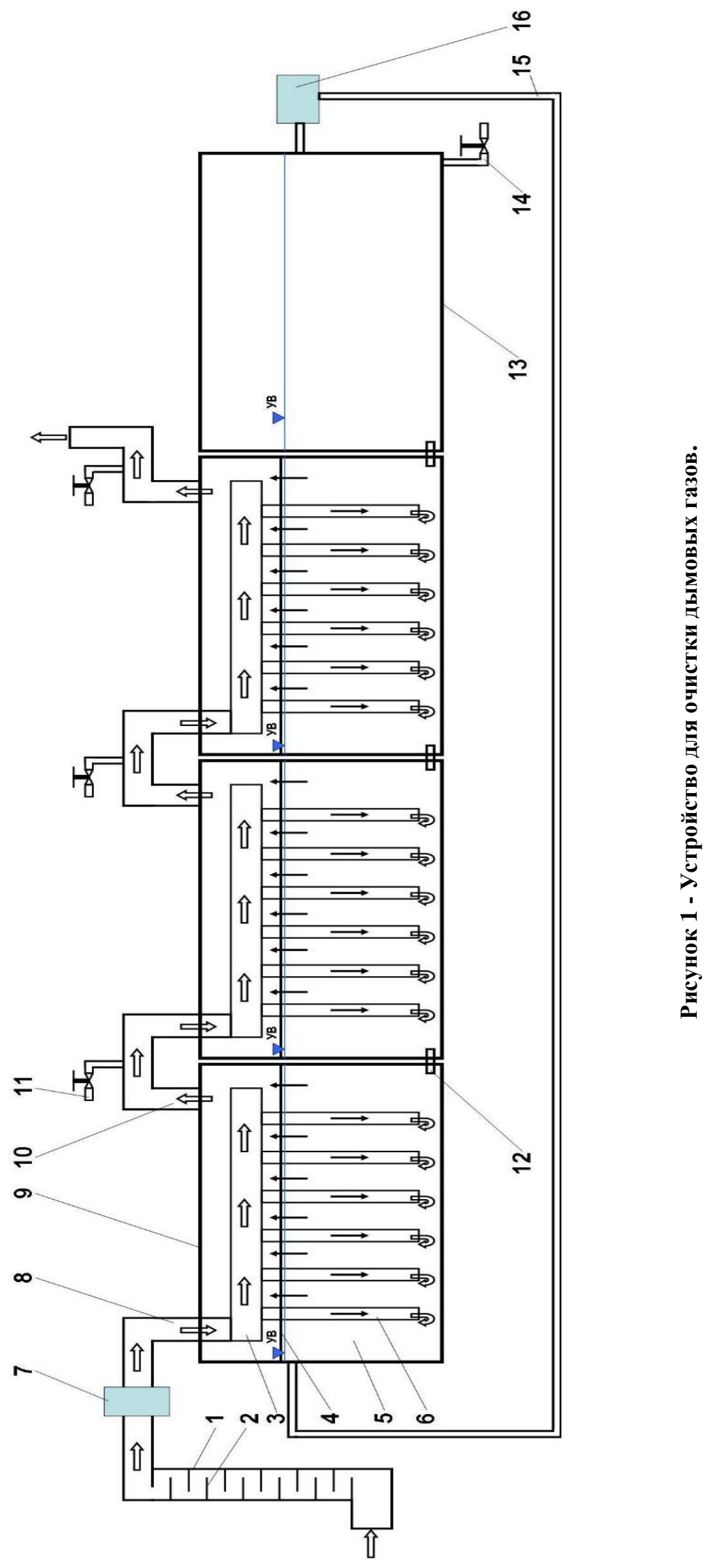




\begin{tabular}{|c|c|c|c|c|c|c|}
\hline Impact Factor: & $\begin{array}{l}\text { ISRA (India) } \\
\text { ISI (Dubai, UAE } \\
\text { GIF (Australia) } \\
\text { JIF }\end{array}$ & $\begin{array}{l}=1.344 \\
=0.829 \\
=0.564 \\
=1.500\end{array}$ & $\begin{array}{l}\text { SIS (USA) } \\
\text { PИНЦ (Russia) } \\
\text { ESJI (KZ) } \\
\text { SJIF (Morocco) }\end{array}$ & $\begin{array}{l}=0.912 \\
=0.234 \\
=1.042 \\
=2.031\end{array}$ & $\begin{array}{l}\text { ICV (Poland) } \\
\text { PIF (India) } \\
\text { IBI (India) }\end{array}$ & $\begin{array}{l}=6.630 \\
=1.940 \\
=4.260\end{array}$ \\
\hline
\end{tabular}

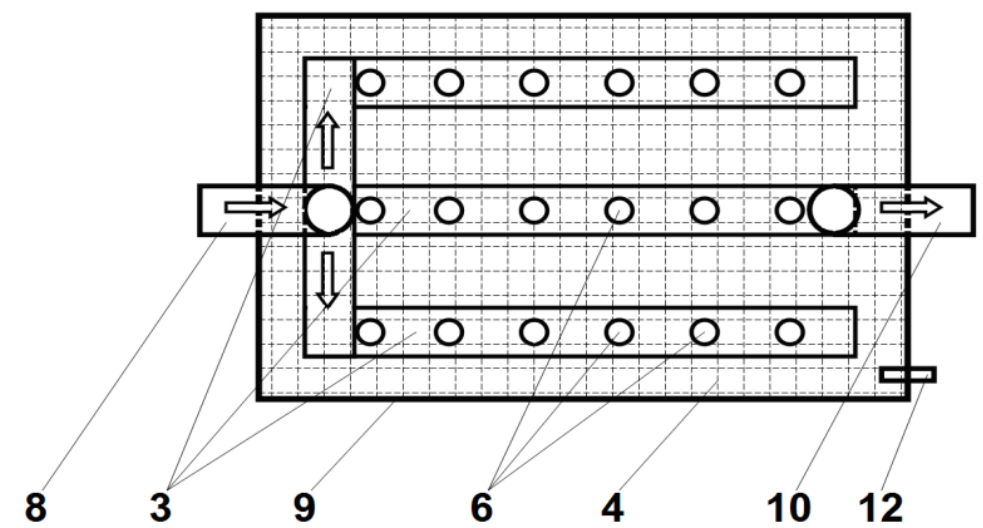

Рисунок 2 - Вид сверху одного закрытого бассейна для очистки дымовых газов.

В верхней части закрытого бассейна увеличивается давление от поднимающегося газа, и газ через выходную трубу 10 проходит к следующей очистной установке. В этой установке процесс очистки повторяется, и так далее дымовые газы переходят от одной установки к другой до полного или требуемого очищения. При переходе газа с одной установки к другой отбираются пробы специальными газоанализаторами 11, этим контролируется состав и уровень очищения газа.

В нижней части каждого бассейна имеется соединительная пропускная трубка 12 для пропуска воды от одного бассейна к другому, а пропускная трубка последней очистной установки соединена с отстойником 13 для загрязненной воды. Имеется общий кран 14, установленный на отстойнике для полного опорожнения всей системы.

Уровень воды в бассейнах поддерживается специальной системой водоснабжения, имеющий насос 16 для повторной закачки воды с верхней части отстойника и трубу 15 , соединенную с первой очистной установкой.

Предлагаемое устройство улучшает очистку дымовых газов, упрощает конструкцию устройства, уменьшает затраты на очистку, увеличивает надежность работы, улучшает экологию и способствует утилизации теплоты при данных работах, тем самым уменьшает воздействие парникового эффекта.

\section{References:}

1. Manapbaev BZ, Betzhanova AZ, Zhalalieva L, Shalkarbaev E, Rysbay D (2014) Meropriyatiya po sovershenstvovaniyu saykling protsessa na mestorozhdenii «Karachaganak» // Materialy respublikanskoy nauchnoprakticheskoy konferentsii «Nauka i sovremennost' - 2014». - Taraz: Taraz universiteti, 2014. - pp. 311-312.

2. Alimbayev BA, Manapbayev BZ, Aliev AD (2015) Features of the development of corrosion in a metal exhaust pipes // Theoretical \& Applied Science. «Industry \& technology Europe», Materials of the International Scientific Practical Conference, 30.05.2015, Lyon, France. - №5 (25), 2015. - pp.140-143.

3. (2011) Innovatsionnyy patent RK №25265. Ustroystvo dlya ochistki dymovykh gazov / Abdrakhmanov S., Shilibek K.Қ., Manapbaev B.Zh., Abdrakhmanov R.S.; Opubl. 20.12.2011., Byul. №12.

4. Shilibek KK, Manapbaev BZ, Zhalalieva L, Rysbay D (2013) Ustroystvo dlya ochistki dymovykh gazov // Materialy respublikanskoy nauchno-prakticheskoy konferentsii «Aktual'nye voprosy obespecheniya ekologicheskoy bezopasnosti». - Taraz: Taraz universiteti, 2013. - pp.67-70.

5. (1987) Avtorskoe svidetel'stvo SSSR №1540073, kl. V01D 47/02, 10.04.87.

6. (1989) Patent №1793945, kl. V01D 47/02 ot 17.03.89.

7. (1977) Avtorskoe svidetel'stvo SSSR №580882, Apparat dlya ochistki gazov / Kadontsev I.I., kl. B 01D 47/00, 1977.

8. (2004) Patent №2079344, k1. B01D047/04. Apparat dlya ochistki gazov / Astanovskiy D.L., Astanovskiy L.Z., Gyunter K.

9. (2006) Patent №2179058, kl. B01D047/06. Apparat dlya ochistki gazov / Izmozherov G.V.

10. (2004) Patent №2108849, kl. B01D047/04. Pylegazoulovitel' - kontsentrator / Petrosov V.K., Tsymbal A.A., Sukhnev V.I. 